Acta Geod. Geoph. Hung., Vol. 38(3), pp. 375-376 (2003)

\title{
EARLIER NOTE OF THE HEIGHT OF AURORAS BY LEONHARD EULER
}

\author{
W SCHRÖDER ${ }^{1}$
}

[Manuscript received February 8, 2002]

\begin{abstract}
From a letter by Leonhard Euler some speculations on the height of auroas in the atmosphere can be derived.
\end{abstract}

Keywords: auroras; Earth's atmosphere; electricity

In earlier times, mostly before the end of the 19th century many speculations has been made on the height of the Earth's atmosphere. Also, scientist discussed the height of the auroras, which has been noted often in Middle Europe. Mostly people thought that the auroras are manifestations of the inner Earth's atmosphere, inside laying in a circle of it. Only few speculations has been made of the exact height and on the nature of this phenomena. They were supposed as signs of God up to the aurora of March 17, 1716 (see for detail Schröder 2001).

An interesting letter of Leonhard Euler (1707-1783), Swiss mathematician and member of the Berlin Academy of Sciences to the theologian and scholar Johann Esaias Silberschlag (1716-1791) who was also a member of the Berlin Academy of Sciences, gibes some more details on the discussion in the 18th century. Euler wrote in his letter that the auroras, similar to the great meteors or fireballs, are placed in the high atmosphere, mostly about the height of the meteors. For Euler it was clear that both phenomena, meteors, fireballs and auroras, are objects which are associated with the Earth's atmosphere. This was at that time a new idea, that the phenomena are caused in the atmosphere and part of the composition of it. Following this, they concluded that the height was about the normally observed clouds. Following this a new scope has been set up and following years shoed that the auroras has not been interpreted as Gods sign, but more as a physical object which was built in the Earth's atmosphere.

\section{Appendix}

EULER LEONHARD, Swiss mathematician and physicist, 1707-1783 (autograph letter with signature), with a small sketch in text, Berlin, November 15, 1763, pp. 3, 4. With lacquer seal and address, last page deficient (losses of text).

Comprehensive letter to the theologian and naturalist Esaias Silberschlag (1710-1791) in Magdeburg, Euler thanks him, as president of the Section Mathematics of the Berlin Academy of Sciences for a "magnificent treatise on fireballs". Following remarks to these topics he continued with considerations on the basic problems of mechanics, on which "metaphisici" had wrong ideas?

${ }^{1}$ Geophysical Commission, Hechelstrasse 8, D-28777 Bremen-Roennebeck, Germany

1217-8977/2003/\$20.00 (C)2003 Akadémiai Kiadó, Budapest 
"... I read this magnificent work with greatest approval and admired the diligence in comparing so many different observations. The fact that this phenomenon occurs in such a great height in the atmosphere was for me not surprising, as we know that the height of the Northern lights is even much greater. The question, if the material of the fireballs is as coarse and of terrestrial origin as your suppose, will be a doubtful case for many. When iour Dr. Pott... once lectured on stellar wonderful jelly-like material, which constitutes these bodies and reported having discovered this material, our naturalists laughed on this... The elasticity of air is without doubt existing, but nobody dared up to now to discuss this problem, I didn't want, however, to attribute it "vires activas". All what had been found about bodies up to now are based one two principles inertiae et impenetrablitatis and all our knowledge on mechanics is also based on these two principles even if the metaphysici who have completely false ideas on the principles of movement and forces are opposed to them. Ever since Leibniz, nobody has among them insight into this science and in Leibniz's time it was mostly unknown. A body in itself remains always in the same condition, be it in rest or in movement. This is the principium inertiae. During this, another body cannot penetrate it; this is the principium inpenetrabilitatis. When the body $\mathrm{B}$ is in rest,

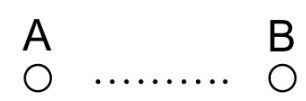

and body A moves with a certain velocity against it, then B wants to remain always in rest, but $\mathrm{A}$ wants to move in a certain direction with some velocity. This would also happen if body A could cross absolutely freely body B but as both are impenetrable, as soon as A touched either A must suddenly remain in rest (what is contrary to inertia) or it must drive B with a certain velocity before itself (the inertia of B is opposed to this), or both must change simultaneously. Without doubt, the last case will happen.

... In my opinion actio and vis activa are attributed to no other substance as to soul and spirit, and in this point bodies and spirits differ much more than if each elemento corporis similar qualities and forces attributes then to a spirit, and there the world of spirits is much higher than that of bodies. Thus nothing common remains and nothing less consistent can be invented than that a body can think. In the world of bodies happens everything necessarily, but in the world of spirits is everything free and thus doubts disappearing with which philosophers fearfully torment themselves ..."

\section{References}

Schröder W 2001: Changes in the interpretation of the aurora - case study of the event of March 17, 1718. Bremen: Science Edition

Euler E 1763: Letter to J E Silberschlag from 15. 11. 1763 (unpublished) 